\title{
Awareness on Diabetes Complications and Protective Measures in Makkah Region among Known Diabetic Patients: A Cross-Sectional Survey
}

\author{
Anoud R. Omer ${ }^{1}$, Abdullah A. Alghamdi ${ }^{2}$, Rakan A. AlYamani ${ }^{2}$, Salman H. Alqurash ${ }^{2}$, Abdulaziz A. \\ Alshikh ${ }^{2}$, Roa'a A. Alshaik ${ }^{2}$, Mohamed E. Salih ${ }^{2}$, Anees A Sindi ${ }^{3,4}$ \\ ${ }^{1}$ Clinical Research Unit, King Abdulaziz University Hospital, Jeddah, Saudi Arabia \\ ${ }^{2}$ Faculty of Medicine, Umm AlQura University, Makkah, Saudi Arabia \\ ${ }^{3}$ Faculty of Medicine, King Abdulaziz University, Jeddah, Saudi Arabia
}

${ }^{4}$ Department of Anesthesia and Critical Care, King Abdulaziz University Hospital, Jeddah, Saudi Arabia

\begin{abstract}
Objective: To explore diabetic patients' awareness on its complications and possible protective measures in the Makkah region. Materials and Methods: A cross-sectional facility-based survey, conducted between August 2015 and January 2016. We targeted diabetic patients who were followed in seven PHC centres in Makkah Region. Results: We included (450) participants in the study. Males constituted (55.3\%), and around two thirds of the group (64\%) were above the age of 30 . Half of the participants (51.6\%) defined diabetes as "a genetic disease related to food and lifestyle. While obesity was the commonest risk factor identified by patients (62.4\%), polyuria was the most reported symptom (78\%). (67.1\%) identified "diet control" as the most important treatment modality, and the top three protective measures widely known were; physical exercise, regular blood monitoring and drug compliance. The first two were the mostly applied on a daily basis, for (40\%) and (54\%) of the participants respectively. Participants enlisted different sources of information on diabetes including: family members, hospitals and PHC centres, Internet and television, medical campaigns and health promotion text messages. Conclusions: Patients demonstrated a good level of awareness on diabetes, however more education must be devoted to complications and adoption of protective measures.
\end{abstract}

Keywords: Awareness, Diabetes, Complications, Makkah

\section{Introduction}

Diabetes Mellitus is a widely spread metabolic disorder worldwide. Over the last thirty years, its global prevalence has been increasing steadily to reach $8.5 \%$ in the year 2014, (1) this was true for both developed and developing countries, and especially for the latter where a more rapid increase was reported. ${ }^{(1)}$ In Saudi Arabia, the prevalence of diabetes was reported at $(17.6 \%),{ }^{(2)}$ in fact, more than 3.4 million citizens were diagnosed with diabetes in the year $2015,{ }^{(3-4)}$ putting Saudi Arabia on the top of countries suffering from diabetes, not only in the region but around the world. ${ }^{(1-4)}$

Many theories and possible aetiologies were related to diabetes involving inadequate insulin production, action or both. This can result in an altered glucose uptake by the human body, and the characteristic chronic hyperglycaemia encountered in diabetic patients. It can induce serious metabolic changes, and damage of multiple organs. (5-6) Thus, many macrovascular and microvascular complications were associated with diabetes. ${ }^{(7)}$ It is considered a major cause of blindness, kidney failure, heart attacks, strokes and lower limp amputations, ${ }^{(1,2-7)}$ and even responsible for 1.5 million deaths annually. ${ }^{(1)}$

Diabetic complications could be prevented by maintaining healthy body weight, regular exercise, healthy diet, and blood glucose control with drug compliance. Ensuring adherence to these measures demands raising patients' awareness on the risks associated with diabetes. ${ }^{(8)}$ The latter must be heavily emphasized and practiced during follow-up visits with attending physicians, nurses, dieticians and diabetes educators. ${ }^{(9)}$ Although studies acknowledged the importance of diabetic education, yet research exploring patients' awareness on complications is still limited. (8) Similarly, many studies in Saudi Arabia highlighted the need to explore patients' knowledge on diabetes, and then strengthen patients' education programs to support patient care across the kingdom. ${ }^{(10)}$ This study aims to explore the awareness of diabetic patients on its complications and protective measures.

\section{Materials and Methods}

The study was a cross-sectional, facility-based survey, conducted between August 2015 and January 2016. We targeted known diabetic patients attending Primary Health Care (PHC) centers in the Makkah region. Ethical approval was obtained from the Research Ethics Committee at the Faculty of Medicine, Um Al-Quaraa University, as well as other necessary administrative approvals in each facility. To enhance the scope of this study, we selected the busiest PHC centres in the region, four in Jeddah city, two in Makkah and one in Al-Taif. We targeted registered diabetic patients when they come for monthly follow-ups. The average number of diabetic patients followed in these facilities was between $(100-120)$ patients per centre per month, and we intended to enroll half of these patients in our study i.e. a total of 420 patients. A walk-in convenience sampling technique was used to recruit participants. All diabetics in 


\section{International Journal of Science and Research (IJSR) \\ ISSN (Online): 2319-7064}

Index Copernicus Value (2015): 78.96 | Impact Factor (2015): 6.391

patients' waiting areas, irrespective of age, gender or other medical complaints, and who agreed to participate in the study were included.

For data collection, and after reviewing international and local literature available on diabetes awareness, we developed an interview-based questionnaire that was tested and validated prior to data collection. Questionnaires were distributed by trained interviewers who explained the purpose of the study, questionnaire's content and assured participants about the data confidentiality data. It was designed to gather information on patients' personal data, and their awareness on 1. disease definition and risk factors, 2. Symptoms \& signs, 3. Complications and finally 4. Treatment modalities and protective methods, including application of the latter. We also included questions about their preferred sources of information. Data obtained from questionnaires were coded, crosschecked and entered on daily basis. Comparative and diagrammatic analysis was conducted using IBM SPSS statistics version 20 software. It must be acknowledged that due to time and resources constrains, we were not able to expand the survey to other cities or centres in the region.

\section{Results}

We included 450 participants in the study, with males constituting $(55.3 \%)$ of participants when compared to females $(44.7 \%)$. Most patients were married $(66.9 \%)$ and around two thirds of the group (64\%) were above the age of 30 years. While $(36.7 \%)$ were university graduates, only a small group of patient were illiterate $(10.2 \%)$. Regarding disease history, $(36 \%)$ of patients were diagnosed within the last 5 years, $(31.6 \%)$ between 5 to 10 years, $(16.9 \%)$ were known diabetics for 10 to 20 years, and only (15.6\%) have been suffering from diabetes for more than 20 years (Table 1). Regarding knowledge about diabetes, participants responded to our questions as follows:

\section{Disease Definition \& Risk Factors}

Several definitions were presented for the participants and were asked to mark all definitions they see suitable for diabetes. More than half of the participants $(51.6 \%)$ defined diabetes as "a genetic disease related to food and lifestyle, and the second most popularly chose definition was "a chronic disease due to high blood glucose level" (49.6\%), followed by "a disease of low insulin level" (47.6\%). Out of the total group, (14.4\%) stated that: "they did not know what is diabetes". Participants were also asked to identify all risk factors associated with diabetes that were known to them. Their responses in order of importance were: obesity as the most common risk factor $(62.4 \%)$, sedentary life style $(55.6 \%)$, family history of diabetes $(53.8 \%)$, uncontrolled diet or bad food habits $(49.8 \%)$, aging $(28.9 \%)$, gestational diabetes $(27.1 \%)$, hypertension $(21.8 \%)$, and smoking (16\%). (Figure 1A)

\section{Symptoms \& Signs}

Regarding patients' awareness on symptoms, polyuria was the most commonly identified symptom (78\%), followed by polydipsia $(70 \%)$, hunger $(40 \%)$, fatigability $(39.1 \%)$, weight loss $(34.2 \%)$ and numbness $(34.2 \%)$. (Figure 1B) A $(6.2 \%)$ of participants could not identify any symptom. For
$(40.2 \%)$ of patients, the normal levels of blood glucose were "100-125 mg/dl", (23.1\%) thought it was between "70-99 $\mathrm{mg} / \mathrm{dl}$ " and only ( $4.7 \%)$ chose " $25-40 \mathrm{mg} / \mathrm{dl}$ ". On the other hand, $(22.4 \%)$ did not know which of the above was the normal range.

\section{Complications}

We asked the participants list all diabetic complications known to them. "Delay wound healing" $(47.3 \%)$ was the most mentioned, then came both "retinopathy" and "amputations" (43\%), next was "strokes" (37.6\%), and "neuropathy" (34.4\%), and lastly (30.4\%) of the total participants felt that "nephropathy" was a serious diabetic complication. Other less mentioned complications included: cardiovascular diseases, urinary tract infections and erectile dysfunction. Around (10\%) were not able to identify any complications. (Figure 2)

We asked these patients to assess their knowledge and awareness on the above complications. Only (12\%) described themselves to be "Extremely aware", (24.2\%) were "highly aware", as "moderately aware" (41.6\%), and $(18.9 \%)$ felt they were only "minimally aware". (3.3\%) acknowledged that they "were not interested to know anything about these complication".

\section{Treatments and Protective Measures}

For diabetes treatment modalities, $(67.1 \%)$ identified "diet control" as the most important treatment modality, followed by "insulin" (60.2\%) and "oral hypoglycaemic drugs" $(51.6 \%)$. We also inquired about protective measures that were known to them, weather against diabetes and/or its associated complications. The top three ranked measures were: "Physical exercise" as the highest reported measure $(71.1 \%)$, secondly was "regular blood glucose monitoring" (69.3\%), and thirdly (58.4\%) viewed "drug compliance" as a protective measure. Other less popular protective measures included: "wearing medical shoes" (36.4\%), "foot care" and "regular ophthalmic follow-ups" both at (28\%), and regular renal functions tests $(25.1 \%)$. (Figure 3)

To assess the adoption of protective measures, participants were asked to estimate the frequency at which they use these protective measures. Two different sets of protective measures were included, home-based and facility-based. "At home Blood glucose monitoring", "physical exercise" and "wearing protective medical shoes" were done mostly daily in $(54 \%),(40 \%)$ and $(40.4 \%)$ of participants respectively. On the other hand, and for the same three measures, (14\%) checked their blood glucose rarely (i.e. once in the last three months), $(22.7 \%)$ exercised also once during the past three months, and (20.4\%) remember they only rarely wear medical shoes. In fact, (29.8\%) stated, "they never wear protective shoes". For measures that demand visiting a health facility, in particular ophthalmology follow-ups, (26\%) of participants visited the ophthalmologist "twice a year", (28.7\%) "once a year" and (46.7\%) admitted they "never go for these follow-ups". Similarly, participants who undertake renal functions test "twice this year" were $(24.7 \%)$, those who did it "once a year" were $(28.7 \%)$, and those said "they never do it" were (46.7\%). (Table 2) 


\section{International Journal of Science and Research (IJSR) \\ ISSN (Online): 2319-7064}

Index Copernicus Value (2015): 78.96 | Impact Factor (2015): 6.391

\section{Diabetes Education}

Regarding sources of information about diabetes, participants enumerated many sources including: family members, hospitals and PHC centres, Internet and television, medical campaigns and health protection text messages. When asked to rank the top three sources per their preference, participants marked "hospitals" (50.7\%) as their best source, then PHC centres (45.6\%), and finally "internet and television" $(35.6 \%)$.

\section{Discussion}

This survey aimed to understand the level of knowledge about diabetes among known patients, especially regarding complications, and while the results showed fair knowledge among the participants, it also indicated that when compared to the disease burden in Saudi Arabia, more awareness is needed to support these patients, and promote their health.

Regarding disease definition, nearly half of participants defined diabetes as a "chronic disease characterized by raised blood glucose levels", agreeing with reports from other studies. Our sample scored much better than other local groups in defining diabetes, one local example is a study conducted in Al-Riyadh in the central region of Saudi Arabia, with only $(24.8 \%)$ defining diabetes correctly. (11) Yet, our rate was still behind when compared to rates reported by other regional studies, including examples from Iraq $(98 \%)^{(12)}$ and Singapore $(83.3 \%){ }^{(13)}$ Definition is considered as basic disease knowledge, and thus there is a need to bring health professionals' attention to its importance, and ensuring it is not missed when counselling newly diagnosed diabetics. Despite the above, our group showed better knowledge about the genetic association of disease, since more than $50 \%$ of patients pointed to the genetic attribution of diabetes when they defined it as "a genetic disease related to food and lifestyle". This corresponded to rates from Al-Riyadh study (53\%), ${ }^{(11)}$ and was much higher when compared with regional rates from $\operatorname{Iraq}(25.5 \%){ }^{(12)}$

Discussing risk factors associated with diabetes, two thirds of participants correctly identified obesity as the most common risk factor followed by family history of diabetes and uncontrolled diet. These answers were very comparable to results of other local studies in Al-Riyadh ${ }^{(11)}$ and AlQuasim $^{(10)}$ and to other regional responses from India. ${ }^{(14)}$ Furthermore, our participants were able to identify the less commonly known risk factors such as gestational diabetes, and these results reflects a good level of information depth and diversity offered by health educators in our settings, and is meant to inform patients about the risk factors of diabetes. The overall awareness of the symptom and signs was also comparable to previous studies, where polyuria and polydipsia were the symptoms most commonly reported. These findings were similar to participants' responses in the above studies. ${ }^{(11-12)}$ However, other common and notable symptoms of diabetes, for example "excessive hunger" and "weight loss" were less mentioned. There is a need to inform patients about these common symptoms of diabetes in order to facilitate earlier and better recognition of cases in the future.
Awareness on diabetic complications among our group was somehow corresponding to that reported in the Iraqi study. (12) While both groups ranked retinopathy and amputations among the top most serious complications, nephropathy was the most reported diabetic complication in another study in Al-Riyadh. ${ }^{(11)}$ Only few members considered themselves "extremely aware" about diabetic complications, and thus highlighting the importance of focusing on it. On the other hand, most participants showed to be quite knowledgeable when asked about the different treatments of diabetes. In fact, two thirds of the group considered "diet control" to be an important treatment intervention, and not merely a protective measure similar to other populations. ${ }^{(11-12)}$ For the latter measures, participants demonstrated high level of awareness on its value, and mentioned a wide range including: physical exercise and regular blood sugar monitoring. Yet, less than half of them confirmed they acutely adopted these measures. More in depth assessment is needed to understand the reasons behind low rates of protection adoption despite acknowledging its importance.

More than half of patients classified "Hospitals" and "Primary Health Care centers, as their main sources of information. This comes in agreement with the other studies. A $(56 \%)$ of a diabetic population in Al-Riyadh also reported physicians as their main source of information on diabetes, (11) whereas more than two thirds of an Iraqi patients' group described medical staff as their main sources of information. ${ }^{(12)}$ Internet and television ranked third among the sources of information. In fact, only one third of this group described media as a preferred means of information, in contrary to the expected, especially since the Saudi population is known to be intensively involved to conventional media, i.e. television and radio, and currently is becoming more and more active in social media. More should be done to utilize both conventional and social media in health education and raising awareness on diabetes, for the public as well as diagnosed patients.

\section{Conclusion}

Our patients demonstrated a good level of awareness on diabetes comparable to other populations, however more education must be devoted to diabetic complications and adoption of protective measures. Different sources of information should be utilized in increasing patient's awareness, including social media.

\section{References}

[1] WHO. Diabetes. Fact Sheet No. 312. Available at: http://www. who.int/mediacentre/factsheets/fs312/en/.

[2] International Diabetes Federation. The 7th edition of the Diabetes Atlas 2015. Middle East Fact sheet. Available at:

http://www.idf.org/sites/default/files/attachments/MEN A\%20factsheet.pdf.

[3] International Diabetic Federation Middle East and North Africa. Diabetes in Saudi Arabia - 2014. Available from: https://www.idf.org/membership/mena/saudi-arabia.

[4] Alqurashi KA, Aljabri KS and Bokhari SA. Prevalence of diabetes mellitus in a Saudi community. Annals of

\section{Volume 6 Issue 1, January 2017




\section{International Journal of Science and Research (IJSR) \\ ISSN (Online): 2319-7064 \\ Index Copernicus Value (2015): 78.96 | Impact Factor (2015): 6.391}

Saudi Medicine. 2011; 31(1):19-23.

[5] American Diabetes Association. Diagnosis and Classification of Diabetes Mellitus. Diabetes Care 2006; 29(suppl 1): s43-s48.

[6] American Diabetes Association. Diagnosis and Classification of Diabetes Mellitus. Diabetes Care. 2011; 34(suppl 1): s62-s69.

[7] Fowler MJ. Microvascular and macrovascular complications of diabetes. Clinical diabetes. 2008; 26(2):77-82.

[8] O'Sullivan EP, Bhargava A, O'Callaghan M, Buckley $\mathrm{U}$, De Faoite $\mathrm{T}$, Moynihan $\mathrm{K}$, Thabit $\mathrm{H}$, et al. Awareness of diabetes complications in an Irish population. Irish journal of medical science. 2009;178(4):401-6.

[9] American Diabetes Association. Standards of medical care for patients with diabetes mellitus. Puerto Rico Health Sciences Journal. 2013; 20(2).

[10] Mohieldein AH, Alzohairy MA and Hasan M. Awareness of diabetes mellitus among Saudi nondiabetic population in Al-Qassim region, Saudi Arabia. Journal of Diabetes and Endocrinology. 2011; 2(2):149.

[11] Al-Dahan SM, Albaik M, Alomran Y, Aldahan F and Albaik S. Awareness and knowledge of diabetes among Al-Wazarat Family Medicine Health Center attendants. American Journal of Research Communication, 2013; 1(12):104-130

[12] Thabit M. Awareness regarding diabetes mellitus and its complications in type 2 diabetic patients. Al-kindy College Medical Journal 2013; 9:25-8.

[13] Wee HL, Ho HK and Li SC. Public awareness of Diabetes mellitus in Singapore. Singapore Med J 2002; 43 (3): 128-134.

[14] Mohieldein A, Alzohairy M and Hasan M. Awareness of diabetes mellitus among Saudi non-diabetic population in Al-Qassim region, Saudi Arabia. Journal of Diabetes and Endocrinology 2011; 2:14-9.

[15] Shahnooshi JF, Shashidhar G, Anita Dadollahi S, Syed Imam R. Awareness of diabetes risk factor \& complications among diabetic population at a tertiary care teaching hospital. World Journal of Pharmacy and Pharmaceutical Sciences 2014; 3:549-60.

Volume 6 Issue 1, January 2017

www.ijsr.net

Licensed Under Creative Commons Attribution CC BY 
Table 1: General Characteristics of the participants

\begin{tabular}{|c|c|c|}
\hline$\%$ & \# of patients & Characteristics \\
\hline \multicolumn{3}{|c|}{ Gender } \\
\hline 55.3 & 249 & Male \\
\hline 44.7 & 201 & Female \\
\hline \multicolumn{3}{|l|}{ Age } \\
\hline 2.9 & 13 & $<15$ years \\
\hline 33.1 & 149 & $15-30$ \\
\hline 27.6 & 124 & $31-45$ \\
\hline 36.4 & 164 & $\geq 45$ \\
\hline \multicolumn{3}{|c|}{ Marital Status } \\
\hline 66.9 & 301 & Married \\
\hline 27.1 & 122 & Single \\
\hline 6 & 27 & Divorced \\
\hline \multicolumn{3}{|c|}{ Education } \\
\hline 10.2 & 46 & Illiterate \\
\hline 8.4 & 38 & Primary school \\
\hline 9.3 & 42 & Preparatory school \\
\hline 35.3 & 159 & Secondary school \\
\hline 36.7 & 165 & University graduate \\
\hline \multicolumn{3}{|c|}{ Patient is living with diabetes for: } \\
\hline 36 & 162 & $>5$ years \\
\hline 31.6 & 142 & $5-10$ years \\
\hline 16.9 & 76 & $10-20$ years \\
\hline 15.6 & 70 & $\geq 20$ years \\
\hline
\end{tabular}

Volume 6 Issue 1, January 2017

www.ijsr.net 


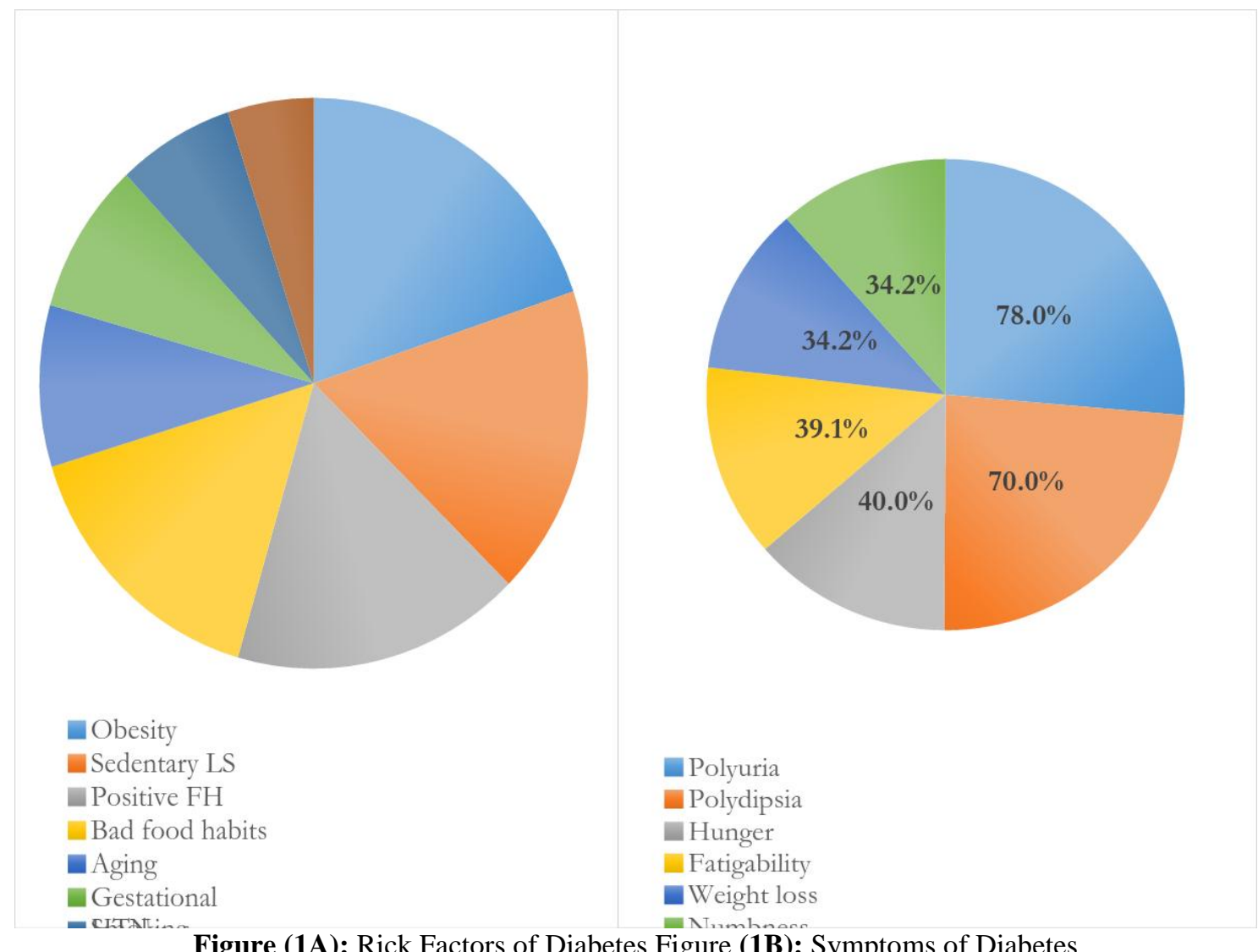

Figure (1A): Rick Factors of Diabetes Figure (1B): Symptoms of Diabetes

Volume 6 Issue 1, January 2017 www.jisr.net 


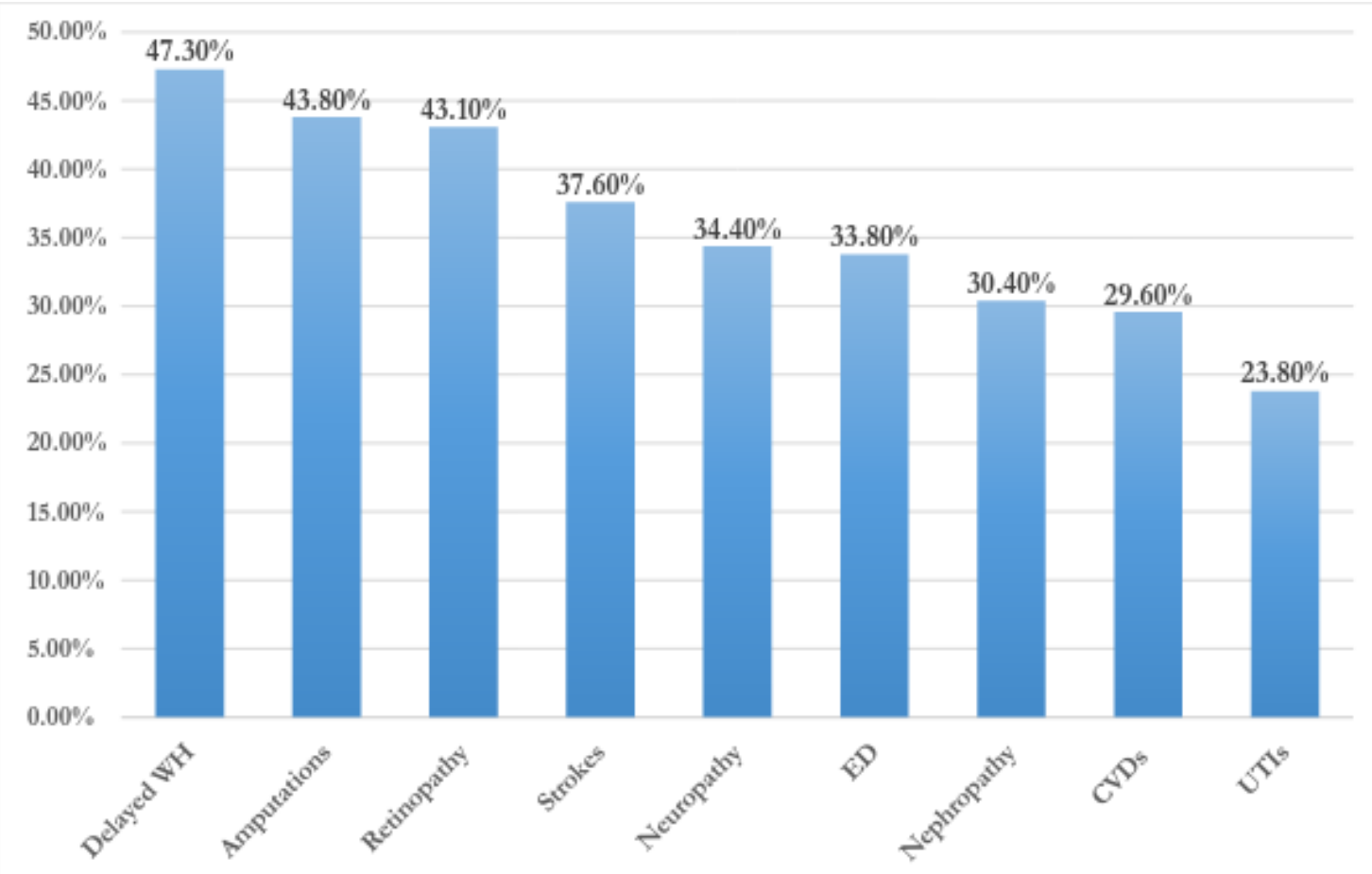

Figure 2: Diabetic complication identified by patients

Volume 6 Issue 1, January 2017 www.ijsr.net 


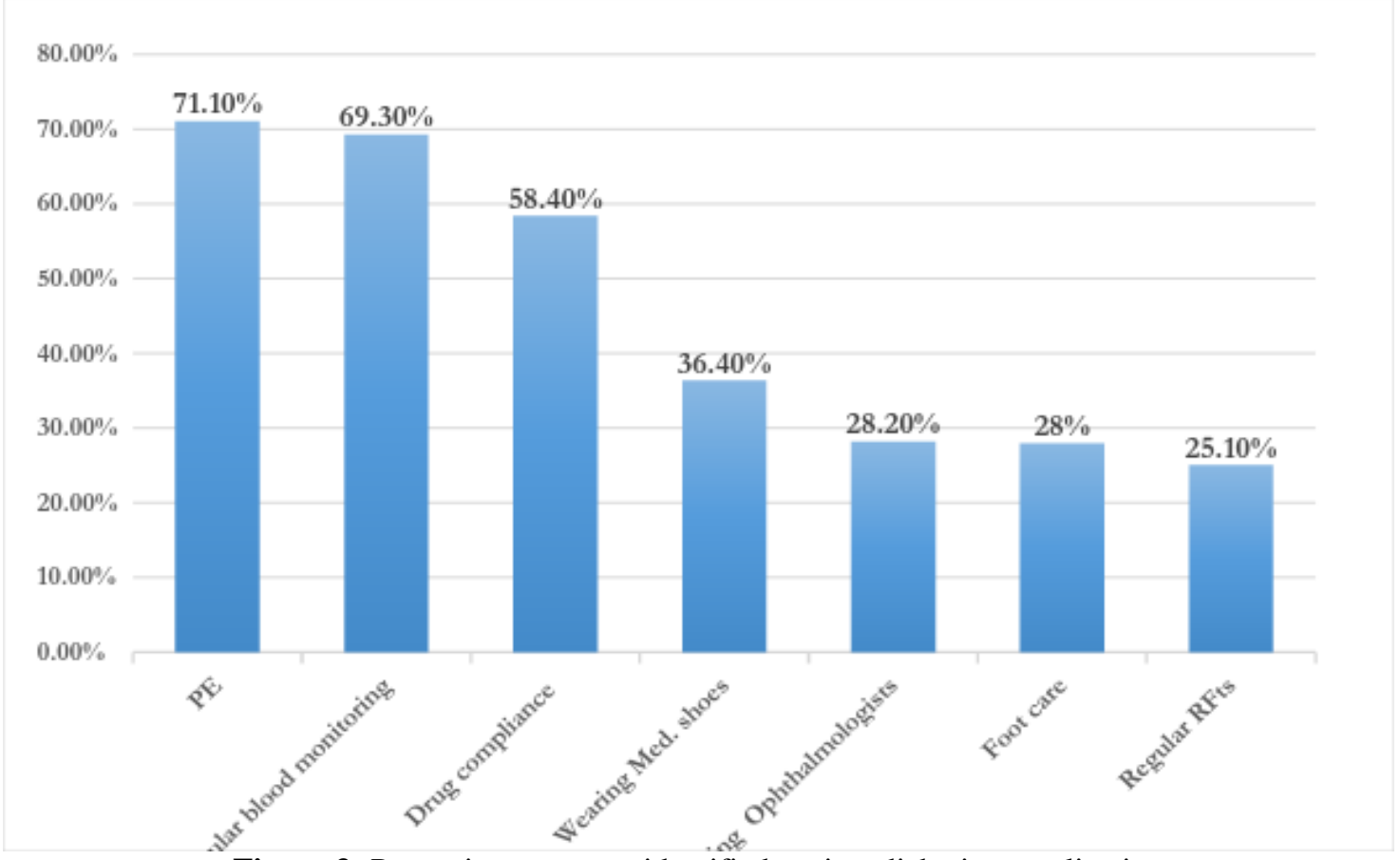

Figure 3: Protective measures identified against diabetic complication

Volume 6 Issue 1, January 2017 www.ijsr.net 
Table 2: Adoption of protective measures

\begin{tabular}{|c|c|c|c|c|}
\hline \multicolumn{4}{|c|}{ Done by patients } & Protective Measure \\
\hline Home-based measures & Rarely & Weekly & Daily & Frequency \\
\hline Never & $22.7 \%$ & $24 \%$ & $40 \%$ & Physical exercise \\
\hline $13.3 \%$ & $14 \%$ & $27.6 \%$ & $54 \%$ & Regular blood monitoring \\
\hline $4.4 \%$ & $20.5 \%$ & $9.3 \%$ & $40.4 \%$ & Wearing medical shoes \\
\hline $29.8 \%$ & $34.7 \%$ & $16.9 \%$ & $22 \%$ & Foot care \\
\hline $26.4 \%$ & \multicolumn{3}{|c|}{ Twice a year } & Frequency \\
\hline Facility-based measures & \multicolumn{2}{|c|}{$26.6 \%$} & Visiting Ophthalmologists \\
\hline Never & \multicolumn{2}{|c|}{$24.6 \%$} & $\begin{array}{c}\text { Regular Renal Function } \\
\text { Tests }\end{array}$ \\
\hline $44.7 \%$ & $28.7 \%$ & & \\
\hline
\end{tabular}

Volume 6 Issue 1, January 2017

www.ijsr.net 